\title{
The liquidity premium in equity pricing under a continuous auction system
}

\author{
GONZALO RUBIO ${ }^{1}$ and MIKEL TAPIA ${ }^{2}$
}

${ }^{1}$ Departamento de Fundamentos, Facultad de Ciencias Económicas, Universidad del País Vasco, Avda. del L. Aguirre 83, 48015 Bilbao, Spain

${ }^{2}$ Universidad Carlos III, Avda. Madrid 126, 28903 Getafe, Spain

The paper shows that the cost of illiquidity is not (positively) priced over all months in the Spanish continuous auction system, where liquidity is provided in the absence of market makers. Two distinct approaches are employed. Both the two-step traditional cross-sectional method and the pooled cross-section time series analysis tend to indicate that the liquidity premium is negative during months other than January. Morever, the liquidity premium in January is positive (although not significant) and at the $10 \%$ level it seems to be significantly higher than the liquidity premium over the rest of the year. Therefore, given the previous results for the US market, we conclude that, independently of the market trading mechanism with the exception of NASDAQ, the behaviour of the relationship between the bid-ask spread and stock returns is rather similar.

Keywords: asset pricing, market microstructure, liquidity premium

\section{INTRODUCTION}

Traditional literature on asset pricing has paid relatively little attention to basic relations between market microstructure and stock prices. Both at the theoretical and empirical levels, papers presenting an explicit link between these two crucial aspects of the finance literature are rather rare. Of course, there are very important exceptions. In their seminal work on asset pricing and the bid-ask spread, Amihud and Mendelson (A\&M) (1986) develop a model with rational investors in which securities with larger bid-ask spreads are priced in such a way that their expected returns are higher. Moreover, A\&M report empirical evidence which seems to be clearly consistent with their theoretical model. This paper has had a tremendous impact on asset pricing. The most intriguing aspect of the paper is probably its ability to explain the size effect. In fact, A\&M, using portfolios of New York Stock Exchange stocks during the 1961-80 period, provide a rational argument to explain the size effect. They show how the positive spread-return relationship persists even after firm size is added as an explanatory variable. In a closely related paper, Amihud and Mendelson (1989) report further evidence consistent with a strong and positive relationship between the bid-ask spread and average returns. 
Surprisingly, researchers have for a long time accepted the empirical evidence of $A \& M$ without questioning either their portfolio formation strategy or their data requirements. Recently, however, Eleswarapu and Reinganum (E\&R) (1993) point out that the A\&M selection criteria to include firms in their pooled crosssection and time series methodology explain their results as an artifact of a seriously limited sample rather than as a consequence of a true positive spreadexpected return relationship. It turns out that the empirical evidence of E\&R suggests a very strong seasonal component of the liquidity premium. They document that, during the 1961-90 period, the liquidity premium is only positive and significantly different from zero in January. ${ }^{1}$ In fact, they find evidence which suggests that the liquidity premium is negative in months other than January. Finally, and in contrast to A\&M, the size effect is significant even after controlling for the bid-ask spread. Unfortunately, this paper confronts financial economists with a new and peculiar puzzle. It is not clear at all why the liquidity premium is positive in January and (basically) negative in other months.

There are three recent papers which argue that the accuracy of the bid-ask spread as a measure of transaction cost is questionable. Eleswarapu (1996) suggests that the NYSE quoted spreads do not reflect the actual cost of transacting since many of the transactions occur inside the quotes. In fact, Petersen and Fialkowski (1994) report very low correlation coefficients between the effective and quoted spreads. Using data from NASDAQ, Eleswarapu shows that, although the spread effect is stronger in the January months, liquidity is also priced in the non-January months. From our point of view, this is an important result. It may reflect the importance of analysing alternative market structures in order to understand the relevance of liquidity. Thus, the dealers' inside spreads on the NASDAQ are likely to be a better proxy of the actual transaction cost relative to the specialist's representative quotes on the NYSE. ${ }^{2}$

At the same time, it is interesting to point out that microstructure literature has experienced enormous development during the last decade. In particular, the information-based models of Kyle (1985) and Glosten and Milgrom (1985) emphasize the information content of trading. Hence, adverse selection becomes the driving force of the empirical literature of microstructure. This provides a new and natural way of exploring the relevance of market microstructure in determining stock returns. This is precisely the strategy followed by Brennan and Subrahmanyam (B\&S) $(1994,1996)$. Following Glosten and Harris (1988) and Foster and Viswanathan (1993), B\&S isolate the adverse selection component of market illiquidity, and test whether the compensation for adverse selection represents an important portion of expected returns. Their evidence suggests a positive and significant relationship between their measure of the cost of illiquidity and average returns. However, their results, as in E\&R, are basically due to the strong seasonality in the compensation for adverse

1 They report similar evidence for the 1981-90 subperiod.

${ }^{2}$ The evidence reported by Huang and Stoll (1996) is also relevant to understand the differences in the empirical results associated with the two market structures. They conclude that there are institutional factors that limit dealers' incentives to narrow spreads on NASDAQ. For comparable firms, execution costs are about twice as large on NASDAQ as on the NYSE. 
selection. As in the previously reported evidence, the only significant positive premium corresponds to January. Moreover, there are significant negative coefficients associated with April and December. At the same time, the usual bid-ask spread variable has additional negative explanatory power in the regressions even after controlling for the adverse selection component. ${ }^{3}$

Given our lack of understanding of the relationship between asset pricing and market microstructure, further research is clearly justified. It is also the case that all previous papers have been done within the context of either the New York Stock Exchange or the NASDAQ. This implies that our empirical evidence is limited to continuous markets with either specialists or competing dealers. It is rather surprising that the relationship between average returns and measures of liquidity (or illiquidity) has not been analysed in markets with different institutional trading arrangements such as the Paris Bourse or the Tokyo Stock Exchange.

In this paper, we use data from the continuous Spanish Stock Exchange auction market to study the liquidity premium on asset pricing. It seems clear that evidence from other countries may provide us with a more precise understanding of the relationship between asset pricing and market microstructure. Also, the fact that the Spanish market is a continuous auction system may help to cover the existing gap in literature regarding the lack of research, within markets in the absence of dealers, related to the importance of the liquidity premium in asset pricing. Hence, to analyse the pricing of liquidity in the absence of dealers becomes the main contribution of our paper.

As pointed out at the beginning of the paper, liquidity has not received the attention it deserves. This is particularly true in a world where institutional investors tend to be involved in global rather than local investing. Portfolio managers are extremely sensitive to illiquidity costs, so that our understanding of the pricing of liquidity in markets where the cost of transacting may be quite crucial for institutions becomes a key issue. In this regard, it should be pointed out that during 1995 and 1996 the institutional investment in Spain represented $63 \%$ and $59 \%$ of the total volume of transactions, respectively. These figures are similar to the percentages found in active markets like the US and Japanese markets. What is important in the case of the Spanish market is that $40 \%$ of the institutional volume is due to foreign investment. Under these circumstances, from the point of view of the Spanish authorities, it is even more relevant to know how liquidity is priced by the market. On the other hand, however, the concern and measurement of liquidity are basically the same in the Spanish market as in most active markets around the world.

This paper employs two distinct methods to analyse the liquidity premium. A traditional two-step cross-sectional regression is first used in order to study the relationship between expected returns and the bid-ask spread. Moreover, this

\footnotetext{
${ }^{3}$ It is interesting to point out that in their 1996 version of the paper, B\&S argue that the spread is a proxy for a risk variable that is associated with (the reciprocal of the price variable. Moreover, accounting for the effects of the stock price level, seasonality in the compensation for adverse selection tends to disappear. Unfortunately, however, B\&S do not justify the rationale of introducing a risk model in which the Fama-French (1993) factors are complemented with a price factor.
} 
framework is also employed to investigate potential seasonalities in the liquidity premium. It should also be noticed that previous literature tends to identify higher (lower) liquidity with smaller (larger) bid-ask spreads. It must be recalled that liquidity effects are unambiguous only when we observe a spread increase (decrease) and a simultaneous depth decrease (increase). ${ }^{4}$ For this reason, our tests incorporate both bid-ask spread and depth as explanatory variables in the well-known two-step cross-sectional regressions.

In order to analyse the robustness of our results, we also employ a GLS pooled cross-section and time series regressions framework. These returns are also adjusted for the Fama-French risk factors estimated for the Spanish market.

Our empirical evidence, independently of the method employed, suggests that liquidity as measured by the bid-ask spread (or bid-ask spread and depth) is not positively and significantly priced in the Spanish market. In fact, the coefficients associated with the bid-ask spread tend to be negative. On the other hand, as in the New York Stock Exchange, we find evidence of a seasonal behaviour in the liquidity premium. It should finally be mentioned that the portfolios formed to mimic the Fama-French factors capture strong common variation in stock returns. However, as with other models, when confronted with multivariate statistics they are shown not to be sufficient to clearly account for the cross-section of expected returns within the Spanish market. In our multivariate statistical framework, the pricing evidence regarding the FamaFrench factors is not conclusive.

This paper is organized as follows. Section 2 briefly describes the main institutional arrangements of the Spanish continuous market system. In Section 3 , our data and the general characteristics of the portfolios employed in the research are discussed. The empirical results based on the traditional two-step cross-sectional approach are reported in Section 4 . In Section 5, we present the results obtained under the alternative GLS pooled cross-section and time series method. Moreover, we also include some mean-variance efficiency tests using the generalized method of moments (GMM) statistics, and the Fama-French risk factors. Finally, we summarize our results and provide some conclusions in Section 6.

\section{BACKGROUND ON THE SPANISH EQUITY MARKET}

Trading mechanisms for equities present alternative characteristics around the world. In general, trading systems can be classified into batch (call) markets and continuous markets. In this paper, we are concerned with a continuous market where a transaction takes place whenever two orders are matched. It is well known that this mechanism provides continuous price information throughout the period in which the market is open. Moreover, continuous markets are either dealer markets or auction markets. Of course, in a dealer market, the trading mechanism is driven by prices with exchange-designated specialists providing liquidity to the market. Ask and bid prices and the number of shares

${ }^{4}$ Depth understood as the number of shares available on each side of the market. See Lee et al. (1993), and Rubio and Tapia (1996) for a detailed analysis. 
available at each quote are offered simultaneously by market makers. It is also the case that specialists are obliged to maintain a limit order book containing the public's limit orders. In the auction system, public trading orders are directly matched against one another. These are markets driven by orders. In 1989, the Spanish Stock Exchange became a continuous auction system by adopting the computer assisted trading system (CATS). ${ }^{5}$ The public's limit orders are displayed in a computer file. In this way, execution against limit orders left on the computerized book is allowed by the trading mechanism. By monitoring available bids and offers on the book, stock exchange agencies (brokers) can execute upcoming orders against an existing bid or offer. Alternatively, they can introduce a new sale or purchase order. Thus, public limit orders represent the available bids and offers. In this sense, the analogue of the bid-ask spread on the continuous auction system is the spread between the best buy and sell limit orders outstanding at any given time. Even without a market maker who continuously establishes quotes, it is the case that when an investor tries to sell any amount of stock, he gets a lower price than the price he has to pay to buy it. In a continuous auction market, agents or speculators trying to absorb temporary imbalances of supply and demand to make a profit will require a premium from buyers and impose an additional compensation on sellers. At the same time, we know that in a mechanism driven by prices, dealers set the spread to protect themselves from traders with better informed individuals. Dealers expect to lose on average to better informed traders and gain on average from transactions with uninformed traders. The same reasoning applies to continuous auction markets throughout the establishment of public limit orders.

The lot market is the most representative way of trading in the Spanish continuous auction system. Priority for crossing a transaction is determined by price. If prices turn out to be equal, then priority is given to the arrival time of the order. Lots are indivisible sets of 25,50 or 100 shares depending on whether the closing price of the security during the previous session is above 5000 pesetas, between 1001 and 5000 pesetas, or below 1001 pesetas. The minimum price variation is 10,5 or 1 peseta for lots of 25,50 or 100 shares. The maximum price variation is $5 \%$ for the opening price, and an additional $10 \%$ for the regular session.

During the sample period employed in this study, market and limit orders represent basically the total number of orders in the market. ${ }^{6}$ As expected, limit orders are the dominant type of order in the Spanish continuous mechanism.

\footnotetext{
5 The Toronto Stock Exchange first adopted this system in 1977. The Tokyo Stock Exchange and the Paris Bourse are also examples of this type of trading mechanism. Hamao and Hasbrouck (1995) and Biais et al. (1995) present a detailed description of the dynamics of trades and quotes for both markets. They also discuss the general institutional characteristics of these markets. Gloston (1994) provides an analysis of the nature of equilibrium of an idealized electronic open limit order book and how it competes against other methods of exchanging securities.

${ }^{6}$ Market orders are to be executed immediately at the best available price, whereas limit orders are orders to buy or sell at a specified price. There exists a third type of order called 'on stop'. They are orders which will be sent to the market conditional on being executed at the proposed price.
} 
From 1991 to 1994 , they represent $89.5 \%$ of all orders sent to the market. It may be useful to point out that $84.7 \%$ of limit orders prevail for one day, and that $44.7 \%$ of all orders are actually crossing operations. Also, $46 \%$ of all orders are introduced in the market during the first two hours of trading. Again, from 1991 to 1994 , the intraday number of orders and transactions present the well known U-shape of trading volume.

The Spanish continuous market is a highly concentrated market. The ten most traded securities represent approximately $60 \%$ of all trading volume. On the other hand, $91 \%$ of all stocks in the continuous market have a daily trading frequency of $85 \%$.

The Spanish market is becoming increasingly important within the European market. In 1994, the total trading volume of the Spanish continuous market was just 2.6\% of the New York Stock Exchange and 6.2\% of the London Stock Exchange. However, it reached $32.2 \%$ of the Paris Bourse. These percentages have been steadily increasing during the last three years.

\section{DATA}

The data employed in this paper are obtained from two sources. The firs: set consists of daily closing transaction prices for 70 companies traded on the continuous Spanish market from 19 April 1990 through 18 October $1994 .^{7}$ This daily data set is used to calculate continuously compounded weekly returns adjusted for dividends and changes of capital structure for each stock in the sample. ${ }^{8}$ At the same time, this data set contains the total number of shares traded in each stock during each day of the sampling period. We also have the number of shares outstanding for each stock at the end of each year from 1989 to 1993. The market return employed is the Madrid Stock Exchange Index which is a value-weighted portfolio where the weights are based on the market value of each asset at the end of the previous year for which the index is calculated.

The second data set consists of the average of the five best daily prices available for both purchases (the ask) and sales (the bid) for the same 70 stocks from 20 December 1990 through 18 October 1994. As we have already pointed out under the adverse selection argument, if the probability that some traders have insider information has increased, liquidity providers may react by either increasing the bid-ask spread or by diminishing the number of shares available on each side of the market (depth). Fortunately, our data contain the number of shares available at each price, again as the average of the five best selling and buying positions in the market. Finally, this data set includes the number of transactions for each of the 70 stocks during each day of the sampling period. Several filters are run on the data in order to eliminate potential data errors.

This information is employed to calculate two daily liquidity characteristics for each of the 70 stocks. The relative spread is the peseta bid-ask spread

\footnotetext{
${ }^{7}$ This sample represents more than $90 \%$ of total trading volume at any time during the sampling period.

${ }^{8}$ Weekly returns are calculated using closing prices from Friday to Friday.
} 
divided by the average of the bid and ask prices. The depth is the sum of the shares available at ask and the shares available at bid.

The empirical results reported in the next two sections of the paper are obtained on the basis of both individual securities and 16 portfolios sorted by relative spread and size. We now explain the portfolio formation strategy and their general characteristics.

For each week of the sampling period, from January 1991 to October $1994,{ }^{9}$ we get the average of the daily relative spread of each security during the previous three months to the reference week. ${ }^{10}$ The 70 stocks are ranked according to their average relative spread at the end of the previous week for which portfolio returns will be calculated, and four portfolios with approximately the same number of assets are obtained. Thus, the individual components of each portfolio change every week.

Given that we want to allow for variation in size that is unrelated to relative spread, we subdivide each spread sorted portfolio into four portfolios, with approximately the same number of securities, on the basis of their market value at the end of the year preceding the portfolio formation strategy. In the end, this procedure yields a total of 16 equally weighted portfolios with 198 weekly returns. Moreover, the value of the relative spread for each portfolio is taken as the equally weighted average of the individual relative spreads.

Table 1 contains the summary statistics for the 16 portfolios sorted by relative spread and size. SP1S1 includes the stocks with the smallest market capitalization within the group with the largest relative spread, and SP4S4 contains the stocks with the largest market value within the group of assets with the smallest relative spread.

Until 1990, the Spanish stock market was characterized by a strong size effect, and the usual January seasonal. ${ }^{11}$ The first aspect to be noticed in Table 1 is the seemingly reversed size effect for the period January 1991 to October 1994. Total returns tend to indicate that large firms obtain, on average, higher returns than small firms. In fact, the average return of portfolio SP4S4 is approximately $20 \%$ per year. This is the largest average return among all 16 portfolios. However, its beta does not seem to suggest that is particularly high relative to other portfolios. On the contrary, and independently of the method employed to estimate betas, its beta tends to be rather low.

A second aspect of interest is that, within each relative spread portfolio, there does not seem to be a clear relationship between relative spread and market value. Unexpectedly, within each spread group, relative spread does not decrease with size. It is also interesting to observe the existence of companies with relatively large market value and with very high relative spread.

\footnotetext{
${ }^{9}$ We have a total of 198 weeks.

${ }^{10}$ We only have reliable bid-ask spread data from the last week of December 1990 . This implies that the average relative spread for the first weeks of 1991 represent an average calculated over less than three months but with an increased number of data points.

${ }^{11}$ See Rubio $(1988,1995)$ and Sentana $(1995 a, 1995 b)$. On the other hand, Basarrate and Rubio (1994) find evidence consistent with the tax-loss selling hypothesis as an explanation of the behaviour of the market during November, December and January.
} 
Table 1 also contains three sets of beta estimates for the 16 portfolios. The first beta reported is the usual ordinary least squares (OLS) estimation with weekly returns. Given that these beta estimates may contain estimation errors related to infrequent trading, betas are also estimated with the method proposed by Fowler and Rorke (F-R) (1983). In particular, the betas reported in Table 1 are given by:

$$
\begin{aligned}
\operatorname{plim} \hat{\beta}_{i}= & \frac{\left(1+\rho_{1}+\rho_{2}\right)}{\left(1+2 \rho_{1}+2 \rho_{2}\right)} \beta_{i+2}+\frac{\left(1+2 \rho_{1}+\rho_{2}\right)}{\left(1+2 \rho_{1}+2 \rho_{2}\right)} \beta_{i+1}+\beta_{i 0} \\
& +\frac{\left(1+2 \rho_{1}+\rho_{2}\right)}{\left(1+2 \rho_{1}+2 \rho_{2}\right)} \beta_{i-1}+\frac{\left(1+\rho_{1}+\rho_{2}\right)}{\left(1+2 \rho_{1}+2 \rho_{2}\right)} \beta_{i-2}
\end{aligned}
$$

Table 1. Summany statistics for the 16 portfolios sorted by size and the average relative spread calculated over the previous three months, for the period January 1991-October 1994. SP1S1 contains the stocks with the smallest market capitalization within the group of stocks with the largest relative spread, and SP4S4 contains the stocks with the largest market capitalization within the stocks with the smallest relative spread. Portfolios are equally weighted. The relative spread of an asset is the peseta bid-ask spread divided by the average of the bid and ask prices. The spreads are based on the average of the five best-bids and the five best-offers of each trading day. The value of the relative spread for each portfolio is taken as the equally weighted average of the individual relative spreads. Average returns are obtained with weekly observations, and betas are estimated with either weekly or quarterly returns. Weekly betas are also estimated by the Fowler and Rorke (F-R) estimation procedure. The market return employed is the Madrid Stock Exchange Index which is a value weighted portfolio where the weights are based on the market value of each asset at the end of the previous year for which the returns are calculated. All figures represent averages over the full period.

\begin{tabular}{lclllll}
\hline & $\begin{array}{l}\text { Average } \\
\text { weekly } \\
\text { return (\%) }\end{array}$ & $\begin{array}{l}\text { Average } \\
\text { relative } \\
\text { spread (\%) }\end{array}$ & $\begin{array}{l}\text { Average } \\
\text { market value } \\
\text { (millions) }\end{array}$ & $\begin{array}{l}\text { OLS beta } \\
\text { (weekly } \\
\text { data) }\end{array}$ & $\begin{array}{l}\text { F-R beta } \\
\text { (weekly } \\
\text { data) }\end{array}$ & $\begin{array}{l}\text { OLS beta } \\
\text { (quarterly } \\
\text { data) }\end{array}$ \\
\hline SP1S1 & 0.069 & 2.889 & 3,384 & 1.383 & 1.757 & $2.0: 4$ \\
SP1S2 & 0.113 & 2.907 & 8,226 & 1.057 & 1.485 & 1.102 \\
SP1S3 & 0.049 & 2.665 & 24,693 & 1.062 & 1.110 & 1.287 \\
SP1S4 & 0.206 & 3.349 & 69,259 & 0.884 & 1.202 & 0.941 \\
SP2S1 & -0.226 & 1.611 & 3,963 & 1.220 & 1.457 & 1.623 \\
SP2S2 & -0.056 & 1.735 & 14,471 & 1.068 & 1.186 & 1.766 \\
SP2S3 & 0.187 & 1.430 & 37,716 & 1.147 & 1.252 & 0.989 \\
SP2S4 & 0.132 & 1.644 & 99,059 & 1.162 & 1.234 & 0.899 \\
SP3S1 & -0.154 & 1.105 & 17,520 & 1.410 & 1.817 & 1.831 \\
SP3S2 & 0.021 & 1.150 & 38,267 & 1.424 & 1.528 & 1.915 \\
SP3S3 & -0.039 & 1.118 & 87,382 & 1.186 & 1.547 & 1.776 \\
SP3S4 & 0.344 & 0.890 & 244,588 & 1.130 & 1.152 & 1.193 \\
SP4S1 & 0.209 & 0.390 & 93,204 & 1.381 & 1.550 & 1.652 \\
SP4S2 & 0.222 & 0.313 & 193,573 & 0.950 & 0.934 & 0.893 \\
SP4S3 & 0.225 & 0.448 & 460,137 & 0.997 & 0.965 & 0.864 \\
SP4S4 & 0.384 & 0.044 & 878,573 & 1.039 & 0.923 & 0.914 \\
\hline
\end{tabular}


where $\beta_{i(+/-) \tau}$ are the beta estimates from a multiple OLS regression of the portfolio returns on the market return with different lags and leads, ${ }^{12}$ and $\rho_{\tau}$ is the serial correlation coefficients for the market index.

As expected, the new estimates tend to increase the portfolio betas in all cases except for portfolios with the smallest relative spread and largest size. In these cases, the F-R estimates tend to be lower than the OLS estimates.

Finally, from our original database, we also calculate quarterly returns. These new returns are used to obtain a third set of beta estimates. The coefficients reported in the last column of Table 1 are based on an OLS regression of quarterly portfolio returns on the market quarterly returns. As before with the F-R methodology, these estimates tend to be higher than the OLS beta estimates. The three sets of betas will be employed in the next section in order to perform our initial tests on the liquidity premium.

\section{THE TRADITIONAL CROSS-SECTION APPROACH}

\subsection{The liquidity premium}

All previous papers investigating the liquidity premium have used portfolios in their regressions. ${ }^{13}$ However, this section of our paper employs individual returns on the weekly cross-sectional regressions of the Fama-MacBeth (1973) type. It has been argued by different authors that empirical results are not always robust to alternative ways of aggregating individual data. ${ }^{14}$

In every week of the sampling period, we run a cross-sectional regression of individual stock returns on a constant, an estimation of beta, and the relative bid-ask spread of each firm. ${ }^{15}$ As before, the relative spread of each asset is the average of the spread calculated over the three months previous to the week in which the cross-sectional regression is performed.

As usual with this type of regression, the main difficulty lies on the beta estimate of the individual stocks. To avoid estimation errors of individual betas, we assign the full-period post-ranking betas of the 16 portfolios described in the previous section to each stock in the sample. In particular, stocks are assigned the beta of the portfolio they are in during the previous week for which the cross-sectional regressions are run. ${ }^{16}$ Note, of course, that this procedure does not imply that a stock's beta is constant. Stocks may move across portfolios according to changes in their relative spreads and market value. Moreover,

\footnotetext{
${ }^{12}$ We did not try to calculate the optimal number of leads and lags by the Akaike specification test. However, our previous experience with this data suggests that the number of leads and lags chosen is sufficient.

The papers by Amihud and Mendelson (1986), Eleswarapu and Reinganum (1993), Brennan and Subrahmanyam $(1994,1996)$, and Eleswarapu (1996).

${ }^{14}$ See, for example, Shanken and Weinstein (1991), Fama and French (1992), and Kothari et al. (1995).

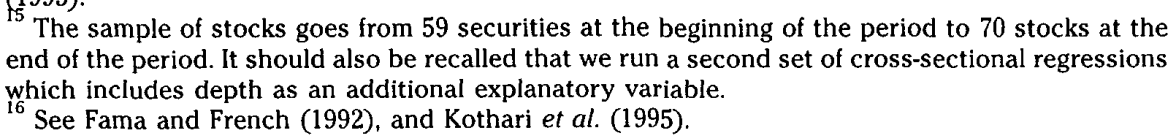


given that we have three alternative sets of betas, our cross-sectional regressions are repeated to make sure that our empirical results are not sensitive to different beta estimation procedures. Following Kothari et al. (1995), it is important to note that inferences from cross-sectional regressions of the type run in our paper can be affected by the return-measurement interval employed to estimate betas. It is well known that true betas vary with the length of the interval used to calculate returns. In fact, Kothari et al. report different results related to the ability of beta in explaining average returns from Fama and French, when annual returns are employed in the estimation of their betas. Given that our full test period is not long enough to use annual returns, we increase the length of the interval from weekly returns to quarterly returns.

The first type of cross-sectional regression we run is given by:

$$
R_{i t}=\gamma_{0}+\gamma_{1} \hat{\beta}_{i t}+\gamma_{2} S P_{i t}+u_{i t} \quad i=1, \ldots, N
$$

where,

$R_{i t}$ is the total return of asset $i$ in week $t$

$\gamma_{0}$ is the return of the zero-beta portfolio (relative to the market portfolio);

$\chi_{1}$ is the market risk premium;

$\beta_{i t}$ is one of the three possible beta estimators described in Section 3;

$\gamma_{2}$ is the liquidity premium;

$S P_{i t}$ is the relative spread of asset $i$ in week $t$, calculated as the average relative spread over the previous three months;

$N$ is the number of individual assets available during each week.

The cross-sectional regression given by Equation 2 is performed for the 198 weeks available in our sample. The average coefficients provide standard FamaMacBeth tests for analysing which explanatory variables are, on average, priced in the Spanish continuous market during the January 1991 to October 1994 period. $^{17}$

The second type of cross-sectional regressions incorporates depth as an additional explanatory variable:

$$
R_{i t}=\gamma_{0}+\gamma_{1} \bar{\beta}_{i t}+\gamma_{2} S P_{i t}+\gamma_{3} D P_{i t}^{1 / 2}+u_{i l} \quad i=1, \ldots, N
$$

where now, $D P_{i t}$ is the depth of each individual stock during week $t$ calculated as the average over the previous three months. The idea is that variations in liquidity (or illiquidity) imply simultaneous and opposite changes in spread and depth. Thus, if there is a liquidity premium, the estimates of $\gamma_{2}$ and $\gamma_{s}$ should be positive and negative, respectively. This may be an important reasoning which may explain previous failures when using the bid-ask spread alone in order to find a positive liquidity premium.

Table 2 contains the empirical results obtained with the regressions described above, and the three alternative full-period portfolio betas. Panel A reports the average coefficients for the full test period from January 1991 to October 1994 Unfortunately, the results are completely disappointing. Moreover, we are not

\footnotetext{
${ }^{17}$ Contrary to all previous papers using this method, our standard errors of the mean of all three coefficients are robust to heteroscedasticity and serial correlation.
} 
Table 2. Estimates of coefficients for the two-step cross-sectional regressions of weekly returns for individual stocks. 198 cross-sectional regressions are run from January 1991 to October 1994. The sample of stocks goes from 59 securities at the beginning of the period to 70 stocks at the end of the period. The relative spread of an asset is the peseta bid-ask spread divided by the average of the bid and ask prices. The spreads are based on the average of the five best-bids and the five best-offers of each trading day. The individual relative spreads employed in the cross-sectional regressions are calculated over the three months previous to the week for which the regressions are performed. The depth is the number of shares available at each price, again as the average of the five best selling and buying positions in the market during each trading day. Depth is also taken as the average over the previous three months. Betas are estimated using the full-period betas of the 16 portfolios sorted by size and the average relative spread. Full-period portfolio betas are estimated with either weekly or quarterly returns. Full-period weekly betas are also estimated by the Fowler and Rorke (F-R) estimation procedure. Stocks are assigned the beta of the portfolio they are in during the previous week for which the cross-sectional regressions are run. Estimates reported are the time-series average of the 198 coefficients obtained throughout the cross-sectional regressions. Robust standard errors are employed to calculate the $t$-statistics reported.

$$
\begin{gathered}
\text { (A) } R_{i t}=\gamma_{0}+\gamma_{1} \beta_{i t}+\gamma_{2} S P_{i t}+u_{i t} \quad i=1, \ldots, 70, t=1, \ldots, 198 \\
\text { (B) } R_{i t}=\gamma_{0}+\gamma_{1} \beta_{i t}+\gamma_{2} S P_{i t}+\gamma_{3} D P_{i t}^{1 / 2}+u_{i t} \quad i=1, \ldots, 70, t=1, \ldots, 198
\end{gathered}
$$

\begin{tabular}{|c|c|c|c|c|c|c|}
\hline \multirow[b]{2}{*}{ Variable $^{1}$} & \multicolumn{3}{|c|}{ Regression $(A)^{2}$} & \multicolumn{3}{|c|}{ Regression $(\mathrm{B})^{2}$} \\
\hline & F-R betas & $\begin{array}{l}\text { Weekly } \\
\text { betas }\end{array}$ & $\begin{array}{l}\text { Quarterly } \\
\text { betas }\end{array}$ & F-R betas & $\begin{array}{l}\text { Weekly } \\
\text { betas }\end{array}$ & $\begin{array}{l}\text { Quarterly } \\
\text { betas }\end{array}$ \\
\hline \multicolumn{7}{|c|}{ Panel A: Full test period: January 1991-October 1994} \\
\hline Constant & $\begin{array}{c}0.565 \\
(2.21)\end{array}$ & $\begin{array}{c}0.803 \\
(2.12)\end{array}$ & $\begin{array}{c}0.535 \\
(2.50)\end{array}$ & $\begin{array}{c}0.585 \\
(1.91)\end{array}$ & $\begin{array}{c}0.810 \\
(1.96)\end{array}$ & $\begin{array}{l}0.531 \\
(2.05)\end{array}$ \\
\hline Beta & -0.279 & -0.493 & -0.244 & -0.293 & -0.503 & -0.242 \\
\hline & $(-1.23)$ & $(-1.34)$ & $(-1.66)$ & $(-1.27)$ & $(-1.36)$ & $(-1.64)$ \\
\hline Spread & -5.116 & -7.437 & -5.529 & -5.227 & -7.421 & -5.624 \\
\hline & $(-0.70)$ & $(-0.94)$ & $(-0.74)$ & $(-0.65)$ & $(-0.86)$ & $(-0.69)$ \\
\hline Depth & - & - & - & -0.00003 & 0.00002 & -0.00002 \\
\hline & & & & $(-0.03)$ & $(0.02)$ & $(-0.02)$ \\
\hline \multicolumn{7}{|c|}{ Panel B: January } \\
\hline Constant & $\begin{array}{c}0.418 \\
(0.52)\end{array}$ & $\begin{array}{l}-0.023 \\
(-0.02)\end{array}$ & $\begin{array}{c}1.222 \\
(1.95)\end{array}$ & $\begin{array}{c}0.303 \\
(0.31)\end{array}$ & $\begin{array}{c}0.019 \\
(0.01)\end{array}$ & $\begin{array}{c}1.125 \\
(1.58)\end{array}$ \\
\hline Beta & $\begin{array}{l}1.481 \\
(1.87)\end{array}$ & $\begin{array}{r}1.956 \\
(1.45)\end{array}$ & $\begin{array}{l}0.786 \\
(1.49)\end{array}$ & 1.397 & $\begin{array}{l}1.782 \\
(1.32)\end{array}$ & $\begin{array}{r}0.712 \\
(135)\end{array}$ \\
\hline Spread & 22.987 & 30.549 & 28.017 & 26.263 & 32.871 & 31.023 \\
\hline & $(0.99)$ & $(1.30)$ & $(1.19)$ & $(1.05)$ & $(1.29)$ & $(1.23)$ \\
\hline Depth & - & - & - & 0.0029 & 0.0021 & 0.0024 \\
\hline & & & & $(0.89)$ & $(0.65)$ & $(0.79)$ \\
\hline & \multicolumn{6}{|c|}{ Panel C: Non-January } \\
\hline Constant & $\begin{array}{c}0.580 \\
(2.15)\end{array}$ & $\begin{array}{c}0.886 \\
(2.25)\end{array}$ & $\begin{array}{c}0.466 \\
(2.06)\end{array}$ & $\begin{array}{c}0.613 \\
(1.90)\end{array}$ & $\begin{array}{c}0.890 \\
(2.07)\end{array}$ & $\begin{array}{c}0.471 \\
(1.71)\end{array}$ \\
\hline Beta & -0.455 & -0.738 & -0.347 & -0.462 & -0.731 & -0.337 \\
\hline & $(-1.95)$ & $(-1.95)$ & $(-2.30)$ & $(-1.95)$ & $(-1.93)$ & $(-2.23)$ \\
\hline Spread & -7.926 & -11.236 & -8.884 & -8.376 & -11.450 & -9.288 \\
\hline & $(-1.03)$ & $(-1.35)$ & $(-1.13)$ & $(-1.00)$ & $(-1.26)$ & $(-1.08)$ \\
\hline Depth & - & - & - & -0.0003 & -0.0002 & -0.0003 \\
\hline & & & & $(-0.29)$ & $(0.16)$ & $(-0.24)$ \\
\hline
\end{tabular}

where $S P_{i t}$ is the relative spread of each stock during each week, and $D P_{i t}$ indicates depth.

\footnotetext{
All figures in percentages

2 The Fowler-Rorke (F-R) estimation procedure is run with weekly returns. The weekly and quarterly betas are OLS estimates
} 
able to find any evidence of a positive liquidity premium independently of the regression employed or the estimate of beta incorporated in the regressions.

The results show a positive and significant zero-beta return, and a negative but non-significant market risk premium. ${ }^{18}$ In accordance with recent results in empirical finance literature and previous analysis of the Spanish equity market, our regressions show that market beta does not help to explain the crosssectional variation in stock returns in the way predicted by the traditional empirically implemented CAPM. As usual, this result may be a consequence of the correlation between the other explanatory variables included in the regressions and the true beta. Unfortunately, similar negative estimations are found when beta alone is used to explain average returns.

The results also show negative coefficients associated with the relative spread variable of individual returns. None of the estimations is significantly different from zero. In any case, these results are close to the findings of E\&R and $\mathrm{B} \& S$ for the US market. ${ }^{19}$ Moreover, contrary to our conjecture, the estimates of the liquidity premium do not change when depth is included in the cross-sectional regressions. In fact, given the coefficients found in the secondpass cross-sectional regressions, the potential economic influence of the depth variable on returns is extremely low.

It may be argued that the sampling period is too short to analyse the variability in the cross-section of average returns. This may be a reasonable explanation. On the other hand, in Spain, beta has never been found to be significantly and positively related to average return. In addition, it should be recalled that previous papers on the liquidity premium face serious problems regarding the availability of bid-ask spread data. ${ }^{20}$ In this sense, our database is more precise. This is particularly the case for the adverse selection component of the B\&S papers, where this variable remains constant over most of the period used in the research, and must be treated as an intertemporal constant. Firially, our interest is centred on the continuous Spanish auction market. In this sense, we must recognize that the historical data available is obviously short.

Panel B reports the average coefficients of the cross-sectional regressions for the weeks in January. As expected, the results change dramatically. Independently of the beta employed in the estimations, the coefficients associated with beta and the relative spread become positive. The significance level of the market risk premium coefficient depends on the method used to estimate fullperiod betas. The most reliable estimate of the market risk premium is obtained when the Fowler-Rorke betas are introduced in the cross-sectional regressions. On the other hand, the liquidity premium for January is positive yet not statistically different from zero. The magnitude of the coefficients is fairly

\footnotetext{
${ }^{18}$ The risk premium estimated with quarterly betas is negative and significantly different from zero at the $10 \%$ level.

19 Similar negative results are obtained when the relative spread is calculated as the average relative spread over just the previous week to the week in which the cross-sectional regressions are run.

${ }^{20}$ In the papers of A\&M and E\&R the relative spread for year $t$ is the average of the beginning and end-of-year spreads in the preceding year $t-1$. Also, the bid-ask prices used are the closing quotes on the days employed in the calculations.
} 
consistent across the alternative beta estimators, although it seems larger when we use OLS weekly betas. ${ }^{21}$ Finally, the depth coefficients are always positive and higher than the estimations over the full test period. As before, the coefficients are not statistically different from zero. It is also interesting to point out the lack of consistency among the estimators of the zero-beta portfolio return. When we use quarterly returns betas and depth is not included in the regression, the zero-beta coefficient is positive, large, and significantly different from zero. In all other cases, its magnitude is much lower and not significantly different from zero.

Panel $\mathrm{C}$ contains the cross-sectional results for months other than January. Of course, the results are much on the line of the findings reported in Panel A. The zero-beta portfolio return is positive and significant for all beta estimators. Negative and significant coefficients of the market risk premium are consistently obtained. Investors, outside January, seem to be negatively compensated for accepting beta risk. This is clearly a disturbing result. Unfortunately, however, we already know that this is not the only disappointing evidence. The liquidity premium tends to be consistently negative, although not statistically different from zero.

In general our results, with the exception of January, provide little support for traditional asset pricing models with or without including a variable related to potential liquidity effects on the market. Statistical differences between market behaviour in January and the rest of the year are fully investigated in the next section.

\subsection{The seasonal evidence}

Given the apparent differences in the behaviour of our asset pricing model between January and months other than January, we formally test whether the coefficients associated with beta and the relative spread are statistically different between January and the rest of the year.

The weekly estimates of the cross-sectional regressions shown in Equations 2 and $3, \gamma_{0}, \gamma_{1}, \gamma_{2}$, and $\gamma_{3}$, are used as dependent variables in the following regressions:

$$
\gamma_{j t}=a+b D_{t}+\omega_{j t} \quad j=0,1,2,3
$$

where, $D_{t}$ is a dummy variable which is equal to 1 if the week belongs to a nonJanuary month and 0 otherwise. In the regression above, $a$, represents the average of the $\gamma_{j}$ coefficient during January, and $b$ is the difference between the rest of the year and January. As before, robust standard errors are employed to calculate the $t$-statistics used in our inferences.

Table 3 contains the empirical results. Panel A presents the average coefficients and their differences for the regression with the relative spread and beta, whereas Panel B includes the depth variable. The first three columns again report the average coefficients for January. Each column corresponds to an

\footnotetext{
${ }^{21}$ It should be recalled that OLS betas present less variations across portfolios than F-R betas or quarterly return betas.
} 
Table 3. Seasonal differences between the estimates of coefficients for the two step cross-sectional regressions of weekly returns for individual stocks. 198 cross-sectional regressions are run from January 1991 to October 1994. The sample of stocks goes from 59 securities at the beginning of the period to 70 stocks at the end of the period. The relative spread of an asset is the peseta bid-ask spread divided by the average of the bid and ask prices. The spreads are based on the average of the five best-bids and the five best-offers of each trading day. The individual relative spreads employed in the crosssectional regressions are calculated over the three months previous to the week for which the regressions are performed. The depth is the number of shares available at each price, again as the average of the five best selling and buying positions in the market during each trading day. Depth is also taken as the average over the previous three months. Betas are estimated using the full-period betas of the 16 portfolios sorted by size and the average relative spread. Fuli-period portfolio betas are estimated with either weekly or quarterly returns. Full-period weekly betas are also estimated by the Fowler and Rorke ( $F-R$ ) estimation procedure. Stocks are assigned the beta of the portfolio they are in during the previous week for which the cross-sectional regressions are run. The weekly estimates of these cross-sectional regressions, $\gamma_{0}, \gamma_{1}, \gamma_{2}$, and $\gamma_{3}$ are used as dependent variables in the following regressions:

$$
\gamma_{j t}=a+b D_{t}+\omega_{j t} \quad j=0,1,2,3
$$

where $D_{t}$ is a dummy variable which is equal to 1 if the week belongs to months other than January and 0 otherwise; a represents the average of the $\gamma$ coefficient during January, and $b$ is the difference between the rest of the year and January. Robust standard errors are employed to calculate the $t$-statistics reported.

Differences between the rest of the year and January

\begin{tabular}{|c|c|c|c|c|c|c|}
\hline \multirow[t]{2}{*}{ Variable $^{1}$} & F-R betas ${ }^{2}$ & $\begin{array}{l}\text { Weekly } \\
\text { betas }^{2}\end{array}$ & $\begin{array}{l}\text { Quarterly } \\
\text { betas }^{2}\end{array}$ & F-R betas & $\begin{array}{l}\text { Weekly } \\
\text { betas }\end{array}$ & $\begin{array}{l}\text { Quarterly } \\
\text { betas }\end{array}$ \\
\hline & \multicolumn{3}{|c|}{ January } & \multicolumn{3}{|c|}{ Differences relative to January } \\
\hline
\end{tabular}

Panel A: Cross-sectional regressions with a constant, beta, and the spread as independent variables

\begin{tabular}{|c|c|c|c|c|c|c|}
\hline Constant & $\begin{array}{l}0.418 \\
(0.52)\end{array}$ & $\begin{array}{l}-0.023 \\
(-0.02)\end{array}$ & $\begin{array}{l}1.222 \\
(1.95)\end{array}$ & $\begin{array}{l}0.162 \\
(0.19)\end{array}$ & $\begin{array}{l}0.910 \\
(0.64)\end{array}$ & $\begin{array}{l}-0.755 \\
(-1.13)\end{array}$ \\
\hline Beta & $\begin{array}{l}1.481 \\
(1.87)\end{array}$ & $\begin{array}{l}1.956 \\
(1.45)\end{array}$ & $\begin{array}{c}0.786 \\
(1.49)\end{array}$ & $\begin{array}{l}-1.937 \\
(-2.35)\end{array}$ & $\begin{array}{c}-2.694 \\
(-1.92)\end{array}$ & $\begin{array}{l}-1.33 \\
(-2.06)\end{array}$ \\
\hline Spread & $\begin{array}{l}22.987 \\
(0.99)\end{array}$ & $\begin{array}{c}30.549 \\
(1.30)\end{array}$ & $\begin{array}{r}28.017 \\
(1.19)\end{array}$ & $\begin{array}{l}-30.914 \\
(-1.26)\end{array}$ & $\begin{array}{l}-41.784 \\
(-1.68)\end{array}$ & $\begin{array}{l}-36.901 \\
(-1.49)\end{array}$ \\
\hline anel & \multicolumn{6}{|c|}{$\begin{array}{l}\text { Cross-sectional regressions with a constant, beta, } \\
\text { independent variables }\end{array}$} \\
\hline Constant & $\begin{array}{l}0.303 \\
(0.31)\end{array}$ & $\begin{array}{l}0.019 \\
(0.01)\end{array}$ & $\begin{array}{l}1.125 \\
(1.58)\end{array}$ & $\begin{array}{l}0.310 \\
(0.30)\end{array}$ & $\begin{array}{l}0.870 \\
(0.58)\end{array}$ & $\begin{array}{l}-0.654 \\
(-0.85)\end{array}$ \\
\hline Beta & $\begin{array}{l}1.397 \\
(1.72)\end{array}$ & $\begin{array}{c}1.782 \\
(1.32)\end{array}$ & $\begin{array}{l}0.712 \\
(1.35)\end{array}$ & $\begin{array}{l}-1.859 \\
(-2.20)\end{array}$ & $\begin{array}{l}-2.514 \\
(-1.79)\end{array}$ & $\begin{array}{l}-1.049 \\
(-1.92)\end{array}$ \\
\hline Spread & $\begin{array}{c}26.263 \\
(1.05)\end{array}$ & $\begin{array}{c}32.871 \\
(1.29)\end{array}$ & $\begin{array}{c}31.023 \\
(1.23)\end{array}$ & $\begin{array}{c}-34.640 \\
(-1.32)\end{array}$ & $\begin{array}{l}-44.321 \\
(-1.64)\end{array}$ & $\begin{array}{l}-40.311 \\
(-1.51)\end{array}$ \\
\hline Dep & $\begin{array}{l}0.0029 \\
(0.89)\end{array}$ & $\begin{array}{l}0.0021 \\
(0.65)\end{array}$ & $\begin{array}{l}0.0024 \\
(0.79)\end{array}$ & $\begin{array}{l}-0.0032 \\
(-0.94)\end{array}$ & $\begin{array}{l}-0.0022 \\
(-0.67)\end{array}$ & $\begin{array}{l}-0.0027 \\
(-0.82)\end{array}$ \\
\hline
\end{tabular}

${ }^{1}$ All figures in percentages

${ }^{2}$ The Fowler-Rorke (F-R) estimation procedure is run with weekly returns. The weekly and quarterly betas are OLS estimates 
alternative beta estimation method. The interest of Table 3 lies in the last three columns, where we report the seasonal differences.

Statistical differences are found for the market risk premium and, less clearly, for the liquidity premium. As expected, given the previous empirical evidence on the Spanish equity market, ${ }^{22}$ the risk premium is significantly higher in January than during the rest of the year. Hence, the behaviour of the compensation for beta risk has a significant seasonal component. At the same time, there exists some evidence of statistically different behaviour of the liquidity premium between January and the rest of the year. In particular, when betas are estimated with OLS weekly returns, and at the $10 \%$ level, the liquidity premium turns out to be statistically higher during January than in the rest of the year. Unfortunately, averages associated with the liquidity premium are estimated with a considerable amount of noise. Therefore, the evidence of seasonal behaviour in the liquidity premium is rather weak. Longer series of data are probably necessary before stronger conclusions can be reached.

In any case, assuming that the liquidity premium does behave differently in January, it might be very difficult to find a reasonable explanation to this phenomenon. E\&R do not offer any intuition or suggestion regarding this type of seasonality. In the Spanish case, an explanation could be related to tax-based trading behaviour at the beginning of each year. Basarrate and Rubio (1994) present fairly conclusive evidence in favour of the tax-loss selling hypothesis. They are able to explain the strong size effect of January seasonality in terms of the behaviour of taxable investors. Again, the weak evidence regarding the seasonality of the liquidity premium might be closely related to tax-based trading. However, formal research would be needed before further conjectures.

\section{THE POOLED CROSS-SECTION TIME SERIES ANALYSIS}

\subsection{Fama-French risk factors and the generalized method of moments mean-variance efficiency estimation}

It has been mentioned earlier that, in previous papers on the Spanish market, beta has not been found to be able to explain average returns. At the same time, mean-variance efficiency of the most popular Spanish value-weighted index has been systematically rejected. Both reasons suggest that additional risk factors should be included in a model whose objective is to account for the crosssection variation in expected returns. Given the recent proposal of Fama and French (1992 and 1993) regarding a three risk factor model of stock returns, this paper investigates the liquidity premium within the context of Fama-French factors.

In order to construct the Fama-French risk factors, we collect the book value data for all 70 companies included in our previously described database. We take the end-of-year book values from 1990 to 1993. Moreover, we take as given the evidence in Fama and French (1992) that book-to-market-equity (BE/ME)

\footnotetext{
${ }^{22}$ See Basarrate and Rubio (1990).
} 
plays a stronger role in explaining average returns. Hence, at the end of every year, we classify all securities in our sample into three portfolios on BE/ME and two on market capitalization. The data needed to form these portfolios are assumed to be known by the market at the end of May following the end of each year in which securities are sorted. This implies that the composition of these five portfolios changes every June. ${ }^{23}$

As in Fama-French (1993), the first factor is the excess market return where the riskless rate of return is given by the weekly repurchase agreement rates of the treasury bill market. As before, the market return is the weekly rate of return of the Madrid Stock Exchange value-weighted index.

In order to obtain the size and $\mathrm{BE} / \mathrm{ME}$ factors, we construct six portfolios (SL, $\mathrm{SM}, \mathrm{SH}, \mathrm{BL}, \mathrm{BM}, \mathrm{BH}$ ) from our five initial portfolios, whose returns can be either value-weighted or equally-weighted. Following Fama and French (1993), these six portfolios are formed from the intersections of the two market equity and the three $\mathrm{BE} / \mathrm{ME}$ groups. In other words, the two market equity portfolios are represented by either $\mathrm{S}$ (small) or $\mathrm{B}(\mathrm{big})$, and the three $\mathrm{BE} / \mathrm{ME}$ groups are given by either L(low), or M(medium), or H(high). From them, we have to identify the corresponding intersections before we can actually calculate the risk factors.

Using the six intersections, we now calculate the size factor as the weekly difference between the simple average of the returns on the three small-stock portfolios and the simple average of the returns on the three big-stock portfolios. On the other hand, the BE/ME factor is obtained as the weekly difference between the simple average of the returns on the two high-BE/MEstock portfolios and the simple average of the returns on the two low-BE/MEasset portfolios. Given that the basic six portfolios can be either value weighted or equally weighted, our size and $\mathrm{BE} / \mathrm{ME}$ risk factors are both value weighted and equally weighted risk factors.

In the first place, we perform OLS time series regressions of the excess returns of our 16 portfolios sorted by the relative spread and size described in the third section of this paper on the Fama-French factors:

$$
r_{p t}=\alpha_{p}+\beta_{p \mathrm{~m}} r_{\mathrm{m} t}+\beta_{p \mathrm{smb}} S M B_{t}+\beta_{p \mathrm{hml}} H M L_{t}+\varepsilon_{p t}
$$

where,

$r_{p t}$ is the weekly excess return on portfolio $p$;

$r_{\mathrm{m} t}$ is the weekly excess return on the market factor;

$\alpha_{p}$ is the Fama-French intercept of portfolio $p$;

$S M B_{\text {, }}$ is the factor meant to mimic the risk factor related to size (small minus big);

$H M L_{t}$ is the factor meant to mimic the risk factor associated with book-tomarket-equity (high minus low);

and $\beta_{p \mathrm{~m}}, \beta_{p s m b}$, and $\beta_{p h \mathrm{ml}}$ are the sensitivities to the three Fama-French factors.

Table 4 contains the results for both value-weighted and equally-weighted risk factors. Several aspects of these results deserve to be mentioned. The intercepts tend to confirm that the usual size effect has been reversed since the

${ }^{23}$ Given that we do not have book equity data for 1989 , the initial composition of these portfolios is the same from January 1991 to May 1992. 
beginning of the continuous market. The only positive and significant $\alpha$ corresponds to very large stocks with the smallest relative bid-ask spread. There are other intercepts which seem to be rather large, but none of them is significantly different from zero at the $5 \%$ level. Joint tests will be performed later in the paper.

Table 4. Estimates of coefficients for the time series regressions of the 16 portfolio returns on one constant, and the three Fama-French risk factors. Regressions with weekly data are run from January 1991 to October 1994. The 16 portfolios are sorted by size and the average relative spread calculated over the previous three months. Portfolios are equally weighted. The relative spread of an asset is the peseta bid-ask spread divided by the average of the bid and ask prices. The spreads are based on the average of the five best-bids and the five best-offers of each trading day. The value of the relative spread for each portfolio is taken as the equally weighted average of the individual relative spreads. The coefficients are estimated with the three Fama-French risk factors where two of the factors are calculated from three book-to-market equity portfolios, and two market value portfolios. These two factors are calculated by using both value weighted and equally weighted portfolios of individual stocks. The market factor is the excess return of the Madrid Stock Exchange Index which is a value weighted portfolio. Robust to heteroscedasticity standard errors are employed to report the statistical significance of the coefficients. The regressions are given by:

$$
r_{p t}=\alpha_{p}+\beta_{p m} r_{\text {mt }}+\beta_{\text {size }} F F_{\text {size }, t}+\beta_{\text {book }} F F_{\text {book }, t}+\varepsilon_{p t}
$$

where $r_{p t}$ is the excess return of portfolio $p ; r_{m t}$ is the excess return of the market factor, $F F_{\text {size,t }}$ is the Fama-French factor associated with size, and $F F_{\text {book,t }}$ is the Fama-French factor associated with book-to-market equity

\begin{tabular}{|c|c|c|c|c|c|c|c|c|c|c|c|c|}
\hline \multirow[b]{2}{*}{ Portfolios } & \multicolumn{6}{|c|}{ Fama-French factors (value weighted) ${ }^{1}$} & \multicolumn{6}{|c|}{ Fama-French factors (equally weighted) $^{1}$} \\
\hline & $\alpha_{\rho}$ & $\beta_{p m}$ & $\beta_{\text {size }}$ & $\beta_{\text {book }}$ & $R_{(\mathrm{m})}^{2}$ & $R_{(F)}^{2}$ & $\alpha_{p}$ & $\beta_{p m}$ & $\beta_{\text {size }}$ & $\beta_{\mathrm{book}}$ & $R_{(\mathrm{m})}^{2}$ & $R_{(F F)}^{2}$ \\
\hline $1 \mathrm{~S} 1$ & 0.1 & $31.187^{\star}$ & $1.294^{\star}$ & 0.8 & $5^{\star} 0.28$ & 0.50 & 0.231 & $1.166^{*}$ & $1.456^{\star}$ & 0.86 & 0.28 & 0.65 \\
\hline & & 300 & $0.884^{*}$ & 0.6 & $6^{*} 0.27$ & 0.44 & 142 & $0.932^{\star}$ & $0.882^{*}$ & 0. & $8^{*} 0.27$ & 0.48 \\
\hline 1 1S3 & 0.031 & $0.962^{\star}$ & $0.799^{\star}$ & 0.024 & 40.39 & 0.58 & 0.085 & $1.029^{\star}$ & $0.751^{*}$ & ${ }^{*}-0.10$ & 0.39 & 0.55 \\
\hline & & 0.8 & 0.6 & 0.141 & & 0.45 & & & $0.538^{*}$ & & & 0.43 \\
\hline S1 & -0.2 & 1. & $1.191^{*}$ & 0.644 & $4 * 0$ & 0.47 & -0 & & $7^{\star}$ & & & 0.64 \\
\hline 32 & -0.0 & 0.9 & $0.910^{*}$ & 0.4 & $2^{*} \mathrm{C}$ & 0.52 & -0 & 0. & 0.8 & 0. & & 0.53 \\
\hline 33 & 0.127 & $71.074^{\star}$ & $0.547^{*}$ & $* 0.139$ & 90.51 & 0.60 & 0. & 1. & $0.404^{*}$ & 0.0 & 0.51 & 0.56 \\
\hline & 0. & 11. & $0.292^{*}$ & * 0.1 & 90. & 0.59 & 0.011 & * & 0.1 & 0. & & 0.57 \\
\hline & -0 & 31 & 0.8 & & & 0.67 & -0 & & $31^{\star}$ & & & 0.64 \\
\hline & & 21. & 0.6 & ${ }^{*}-0.0$ & & 0.71 & & & & & & 0.67 \\
\hline & -0.1 & 51.1 & $0.269^{\star}$ & * 0.0 & 00 & 0.63 & -0 . & & 0.1 & & & 0.61 \\
\hline & $0.20 s$ & $1.126^{*}$ & 0.041 & -0.018 & 90.67 & 0.67 & 0.199 & 1.1 & -0.021 & -0 & 0.67 & 0.67 \\
\hline$\$ 1$ & 0.113 & 31.33 & $0.266^{*}$ & $* 0.26$ & $4^{*} 0.71$ & 0.73 & 0.092 & 2.3 & 0.102 & 0. & & 0.72 \\
\hline & 0.067 & 7 0.939* & 0.035 & 0.120 & $0^{\star} 0$. & 0.67 & 0.0 & 0.9 & -0.027 & 0. & & 0.67 \\
\hline 3 & & 61. & 0. & 0. & 20 & 0.79 & 0.0 & +1.0 & $-0.117^{*}$ & & & 0.79 \\
\hline SP4S4 & 0.202 & $2^{*} 1.068^{*}$ & $0.219^{*}$ & ${ }^{*}-0.0$ & & 0.87 & 0.206 & $\xi^{*} 1.048^{*}$ & $-0.125^{\star}$ & 0 & 4 & 0.85 \\
\hline
\end{tabular}

${ }^{1}$ The $\alpha s$ are reported in percentages. $R_{(m)}^{2}$ and $R_{(F F)}^{2}$ are the adjusted $R$-squares for the time series regressions with the excess return of the market as the only factor, and the adjusted $R$-squares for the time series regressions with the Fama-French factors respectively.

* Indicates statistical significance at the $5 \%$ level 
At the same time, we observe that the coefficients associated with the size factor tend to be positive and significant for most portfolios. Interestingly, these coefficients become negative and significantly different from zero for the two largest portfolios with relatively small bid-ask spreads. As expected, given the motivation behind this risk factor, large and highly liquid portfolios are able to hedge the risk associated with size, while small and illiquid assets are very sensitive to this factor. The magnitude of their coefficients is even higher than the market beta. Moreover, the implications are the same regardless of the weighting scheme used in the Fama-French factors. In general, this evidence suggests that the size factor plays an important role in the pricing behaviour of risky assets.

The BE/ME also plays a relevant role in the Spanish equity market. However, it does not seem to be as dominant as the risk factor associated with size. There are only six portfolios whose coefficients are positive and significant with both weighting procedures. They are always the two smallest portfolios within each bid-ask spread category. This suggests that this factor is important for small stocks rather than for relatively illiquid assets, even after the risk factor has been controlled for. As before, the magnitude of the coefficients associated particularly with small stocks is very high compared with other portfolios. In any case, these coefficients tend to be lower than the coefficients of the size risk factor. At the same time, there exists some evidence which may indicate that the $\mathrm{BE} / \mathrm{ME}$ coefficients associated with large and highly liquid portfolios are negative and significantly different from zero. Again, these assets may hedge the risk behind the unobservable factor which the $\mathrm{BE} / \mathrm{ME}$ is meant to mimic.

Table 4 also reports the adjusted R-squares for the time series regressions with the excess market return as the only factor, and the adjusted R-squares for the regressions with the Fama-French risk factors. It may safely be argued that there is a relevant improvement in the variability of portfolio returns explained by the Fama-French risk factors over the market factor. As expected, giver the slopes on the size and $\mathrm{BE} / \mathrm{ME}$ factors, it is not surprising that adding the two returns to the regressions results in considerable increases in the R-squares. Moreover, the major impact occurs in the small and less liquid stocks. For the market alone, the average R-square for the eight portfolios with the highest bidask spread is 0.365 . However, for the Fama-French factors, the R-squares are 0.519 and 0.551 for the value-weighted and equally-weighted cases respectively.

Finally, except for the two largest portfolios with low bid-ask spread, adding the risk factors to the regressions tends to decrease the market beta.

Given these results, we may be tempted to recommend the use of the FamaFrench risk factors in future event studies, portfolio performance evaluation or even calculations for the cost of capital when using Spanish equity data. ${ }^{2:}$

\footnotetext{
${ }^{24}$ See MacKinlay (1995) for an excellent discussion against this kind of argument. In his own words 'the apparent success in identifying a better model may also have come from finding a good withinsample fit through data-snooping. The likelihood of this possibility is increased by the fact that the additional factors lack theoretical motivation'. It should be pointed out that finding a reasonable pricing success of the Fama-French factors in other equity markets works against MacKinlay's argument.
} 
Of course, the fact that we have found an apparent improvement in equity pricing using the previous three risk factors over the traditional market model, does not imply that the model itself is the 'correct' model. We should also test whether the intercepts in the regressions above are jointly equal to zero. We can test this restriction using either the Gibbons et al. (1989) statistics or the GMM methodology proposed by MacKinlay and Richardson (1991). ${ }^{25}$

The first statistic is given by:

$$
W=\left(\frac{T(T-N-K)}{N T}\right)\left(1+\bar{r}_{k}^{\prime} \bar{S}^{-1} \bar{r}_{k}\right)^{-1} \bar{\alpha}_{k}^{\prime} \bar{\Sigma}^{-1} \hat{\alpha}_{k}
$$

which is exactly distributed as an $F(N, T-N-K)$, where,

$T$ is the number of observations over time (198 in our case);

$N$ is the number of portfolios employed in the test (16 in this application);

$K$ is the number of factors (three Fama-French risk factors);

$\bar{r}_{k}$ is the K-vector of factor sample means;

$S$ is the sample maximum likelihood variance-covariance matrix of the factors;

$\hat{\Sigma}$ is the full variance matrix of residuals $\left(\varepsilon_{\mathrm{pt}}\right)$ with $T-K$ in the denominator; and $\hat{\alpha}_{k}$ is the $N$-vector of estimates of $\alpha_{p}$ s.

Alternatively, there are two ways of testing our restriction using the GMM statistic. The first alternative consists in estimating the unrestricted system first ${ }^{26}$ and then testing the null hypothesis that $\alpha_{p}=0$ using the unrestricted estimates. The second possibility estimates first the restricted system under the specification that $\alpha_{p}=0$. This, of course, generates the well-known problem of overidentification since we have more equations $(4 N)$ than parameters $(3 N)$ to be estimated.

Table 5 contains the results of applying the GMM statistics described in the appendix, and the statistic given by Equation 6 to our data. Moreover, the tests are run for the value-weighted and equally weighted Fama-French factors. The GMM statistics are scaled by $(T-N-K) / T$ to improve their finite sample behaviour. As can be appreciated from the table, practically all tests reject at the $10 \%$ level the null hypothesis that the intercepts are jointly equal to zero. ${ }^{27}$ However, with the exception of the restricted GMM statistics with value weighted Fama-French factors, we are not able to reject the null hypothesis at the $5 \%$ level. Therefore, the results in Table 5 show that the Fama-French risk factors are not sufficient to clearly explain the cross-section of average returns on the 16 portfolios sorted by relative spread and size. This might potentially be an important result for the asset pricing model with the bid-ask spread as an additional variable. Hence, we next formally test whether these results can be attributed to differences in the bid-ask spread across our portfolios.

\footnotetext{
${ }^{25}$ These tests may be interpreted, within the context of Grinblatt and Titman (1987), as testing that there is one portfolio of the three reference portfolios (risk factors) that is globally mean-variance efficient.

${ }_{27}^{26}$ Running the regressions given by Equation 5 with an intercept.

${ }^{27}$ Similar results were found for the Madrid Stock Exchange value-weighted index.
} 
Table 5. Mean-variance efficiency tests with 16 portfolios sorted by size and the average relative spread calculated over the previous three months, for the period January 1991-October 1994. Portfolios are equally weighted. The relative spread of an asset is the peseta bid-ask spread divided by the average of the bid and ask prices. The spreads are based on the average of the five best-bids and the five best-offers of each trading day. The value of the relative spread for each portfolio is taken as the equally weighted average of the individual relative spreads. Statistics are obtained with weekly observations. Three test statistics are presented below: the F-test statistic of Gibbons, Ross, and Shanken, and the restricted and unrestricted versions of the GMM statistics suggested by Mackinley and Richardson. In the GMM tests, the statistics are scaled by $(T-N-K) / T$ to improve their finite sample behaviour. The three test statistics are based on $\alpha$ s estimated with the three FamaFrench risk factors where two of the factors are calculated from three book-to-market equity portfolios, and two market value portfolios. These two factors are calculated by using both value-weighted and equally weighted portfolios of individual stocks. The market factor is the excess return of the Madrid Stock Exchange Index, which is a value weighted portfolio $\mathrm{p}$-value in parenthesis.

\begin{tabular}{lcc}
\hline Statistics & $\begin{array}{l}\text { Fama-French factors } \\
\text { (value weighted) }\end{array}$ & $\begin{array}{l}\text { Fama-French factors } \\
\text { (equally weighted) }\end{array}$ \\
\hline F-test $(\mathrm{W})^{1}$ & 1.4979 & 1.5693 \\
& $(0.1043)$ & $(0.0810)$ \\
Unrestricted GMM $\left(\Phi_{1}\right)^{2}$ & 24.5270 & 24.6779 \\
& $(0.0786)$ & $(0.0757)$ \\
Restricted GMM $\left(\Phi_{2}\right)^{3}$ & 27.1493 & 25.3214 \\
& $(0.0399)$ & $(0.0644)$ \\
\hline
\end{tabular}

${ }^{1}$ Under the null hypothesis is distributed $F_{16,179}$

${ }^{2}$ Under the null hypothesis asymptotically distributed $\chi^{2}{ }_{16}$. It does not include the restrictions $\alpha_{p}=0$ in the model

${ }^{3}$ Under the null hypothesis asymptotically distributed $\chi^{2}{ }_{16}$. It includes the restrictions $\alpha_{p}=0$ in the model

\subsection{The liquidity premium and the Fama-French risk factors}

Despite the fact that the evidence reported in Section 4 suggests that liquidity is not positively priced in the Spanish continuous market, at least during months other than January, it should be recalled that the traditional two-step crosssectional tests contain the well-known errors-in-variable problem.

As B\&S (1994) point out, it might be advisable to perform pooled crosssection time series regressions of the 16 portfolio excess returns on the cost of illiquidity measured by the bid-ask spread and the three Fama-French factors. In this way, of course, we are able to estimate simultaneously the coefficients associated with the risk factors and the liquidity premium.

Let $r$ be a $(16 T \times 1)$ vector of the 16 portfolio excess returns, where $T$ is the total number of weekly observations, 198, and the first 16 observations are the excess returns of the 16 portfolios during week 1 .

We next define the following partitioned matrix:

$$
X=[L F]
$$


where $F$ is a $(16 T \times 48)$ matrix of the Fama-French risk factors. Thus, for each of the 198 observations, we have three $16 \times 16$ diagonal matrices, one for each of the three Fama-French factors. ${ }^{28}$ The first 16 columns of $F$ represent the $T$ stacked $(16 \times 16)$ diagonal matrices with identical elements $r_{\mathrm{m} t}$, the market excess return in week $t$. The second 16 columns consist of the size factor, and the last 16 columns have the $\mathrm{BE} / \mathrm{ME}$ factor. On the other hand, $L$ is a $(16 T \times(1+1))$ matrix whose first element is a vector of ones and the remaining $l$ columns are the vectors of the 1 liquidity measures employed. In this section, 1 will be just the bid-ask spread ( 1 equals 1). Given the evidence found previously, we do not include depth as an additional liquidity characteristic.

We next perform the following GLS pooled cross-section time series regressions:

$$
r=X \beta+\varepsilon
$$

where $\beta$ is a $1+49$ vector of coefficients. Note that we have 48 coefficients associated with the 16 portfolios and the three risk factors, one constant, and the 1 liquidity measures. Also, $\varepsilon$ is a $16 T \times 1$ vector of errors.

It should be pointed out that the GLS estimator of the beta coefficients is given by

$$
\widehat{\beta}=\left(X \hat{\Omega}^{-1} X\right)^{-1} X \hat{\Omega}^{-1} r
$$

where the matrix $\Omega$ is a $(16 \mathrm{~T} \times 16 \mathrm{~T})$ block diagonal matrix which can be estimated from the residuals of regression 7 when performed by OLS. Note that for each week, the typical element of $\Omega$ is a $16 \times 16$ variance-covariance matrix of residuals from regression 7 .

This method is applied with and without the relative bid-ask spread variable, which is based again on the average of the individual spreads over the previous three months to the reference week. In this case, of course, we use portfolios, so that the relative spreads finally employed in these regressions are taken, as in Section 1 , as the equally weighted average of the individual relative spreads which belong to each of the 16 portfolios.

Table 6 contains the empirical results. The first aspect of interest to be noticed is that, independently of whether or not the liquidity variable is included and the weighting scheme used for the risk factors, the intercepts are positive and significantly different from zero. This might suggest a lack of statistical power of some of the tests employed in our previous multivariate analysis. Additionally, Table 6 suggests that the liquidity variable, as measured by the relative bid-ask spread, does not eliminate the significance of the intercepts.

This result is not surprising given the lack of significance of the liquidity premium. As before, the premium over all months is negative, but not significantly different from zero. The magnitude of the estimated liquidity premium seems to depend on the weighting characteristics of the factors. When

${ }^{28}$ Note that $(16 T \times 48)$ corresponds to $(T \times 16) \times(16 \times 3)$. We have 16 portfolios and three risk factors. 
Table 6. Estimates of coefficients for the GLS pooled cross-section time series regressions of the 16 portfolio returns on a constant, the three Fama-French risk factors, and the relative bid-ask spread as the measure of the cost of illiquidity. Regressions with weekly data are run from January 1991 to October 1994 . The 16 portfolios are sorted by size and the average relative spread calculated over the previous three months. Portfolios are equally weighted. The relative spread of an asset is the peseta bid-ask spread divided by the average of the bid and ask prices. The spreads are based on the average of the five best-bids and the five best-offers of each trading day. The value of the relative spread for each portfolio is taken as the equally weighted average of the individual relative spreads. The coefficients are estimated with the three Fama-French risk factors where two of the factors are calculated from three book-to-market equity portfolios, and two rnarket value portfolios. These two factors are calculated by using both value weighted and equally weighted portfolios of individual stocks. The market factor is the excess return of the Madrid Stock Exchange Index which is a value weighted portfolio. t-statisties in parentheses.

\begin{tabular}{|c|c|c|c|c|}
\hline \multirow[b]{2}{*}{ Variable $^{1}$} & \multicolumn{2}{|c|}{ GLS regressions without spread } & \multicolumn{2}{|c|}{ GLS regressions with spread } \\
\hline & F-F factors (NW) & $F-F$ factors $(E W)$ & $\mathrm{F}-\mathrm{F}$ factors $(\mathrm{VW})$ & $F-F$ factors (EW) \\
\hline Constant $(\alpha s)$ & $\begin{array}{c}0.100 \\
(3.87)\end{array}$ & $\begin{array}{c}0.113 \\
(4.42)\end{array}$ & $\begin{array}{c}0.135 \\
(3.51)\end{array}$ & $\begin{array}{l}0.124 \\
(3.41)\end{array}$ \\
\hline Spread & - & - & $\begin{array}{c}-4.300 \\
(-1.21)\end{array}$ & $\begin{array}{l}-1.330 \\
(-0.43)\end{array}$ \\
\hline
\end{tabular}

${ }^{1}$ All figures in percentages. The coefficiences of the Fama-French factors are not reported to save space.

the Fama-French factors are obtained with value weighted portfolios, the coefficient is quite close to the estimates reported in Table 2.

Finally, the pooled cross-section time series approach is also employed to provide further evidence regarding the seasonal behaviour of the liquidity premium. In this case, we have two possibilities: 1 is now either two or twelve. This is to say, we may either estimate the model with 12 dummy variables, one for each month, or we may run the GLS regressions with two dummies which correspond to January and the rest of the year. In any case, note that in each week over the sample period, we multiply each dummy variable by the relative bid-ask for that particular weekly observation.

The results using value weighted Fama-French factors are shown in Table 7. Again, the intercepts are positive and significantly different from zero. Moreover, the liquidity premium for the rest of the year is negative and significant. It is interesting to recall that our previous evidence indicated a negative, but nonsignificant premium. Although nine months present negative coefficients, Table 7 suggests that the negative premium is particularly due to July and November. On the other hand, the liquidity premium in January remains positive but insignificantly different from zero.

This seemingly different behaviour of the liquidity premium throughout the year is an empirical finding which deserves further research. It is not clear, however, whether research should be directed toward understanding why different trading mechanisms (with and without market makers) do not seem to 
Table 7. Seasonal estimates of coefficients for the GLS pooled cross-section time series regressions of the 16 portfolio returns on a constant, the three Fama-French risk factors, and seasonal dummies for each month of the year multiplied by the relative bid-ask spread of each portfolio as the measure of the cost of illiquidity. Regressions with weekly data are run from January 1991 to October 1994. The 16 portfolios are sorted by size and the average relative spread calculated over the previous three months. Portfolios are equally weighted. The relative spread of an asset is the peseta bid-ask spread divided by the average of the bid and ask prices. The spreads are based on the average of the five bestbids and the five best-offers of each trading day. The value of the relative spread for each portfolio is taken as the equally weighted average of the individual relative spreads. The coefficients are estimated with the three Fama-French risk factors where two of the factors are calculated from three book-to-market equity portfolios, and two market value portfolios. These two factors are calculated by using both value weighted and equally weighted portfolios of individual stocks. The market factor is the excess return of the Madrid Stock Exchange Index, which is a value weighted portfolio. $t$-statistics in parentheses.

\begin{tabular}{|c|c|c|}
\hline Variable $^{\dagger}$ & $\begin{array}{l}\text { GLS regressions with } \\
\text { January and rest-of-the- } \\
\text { year seasonals } \\
\text { Fama-French factors (NW) }\end{array}$ & $\begin{array}{l}\text { GLS regressions with } \\
\text { monthly seasonals } \\
\text { Fama-French factors }(\mathrm{NW})\end{array}$ \\
\hline Constant ( $\alpha s)$ & $\begin{array}{c}0.143 \\
(3.71)\end{array}$ & $\begin{array}{c}0.140 \\
(3.59)\end{array}$ \\
\hline Spread January & $\begin{array}{c}6.770 \\
(1.00)\end{array}$ & $\begin{array}{c}6.530 \\
(0.98)\end{array}$ \\
\hline Spread rest of the year & $\begin{array}{c}-13.500 \\
(-1.92)\end{array}$ & - \\
\hline Spread February & - & $\begin{array}{l}-5.570 \\
(-0.72)\end{array}$ \\
\hline Spread March & - & $\begin{array}{l}-5.460 \\
(-0.63)\end{array}$ \\
\hline Spread April & - & $\begin{array}{l}-3.200 \\
(-0.35)\end{array}$ \\
\hline Spread May & - & $\begin{array}{c}1.050 \\
(0.11)\end{array}$ \\
\hline Spread June & - & $\begin{array}{c}10.990 \\
(1.07)\end{array}$ \\
\hline Spread July & - & $\begin{array}{c}-18.690 \\
(-1.99)\end{array}$ \\
\hline Spread August & - & $\begin{array}{l}-8.930 \\
(-1.00)\end{array}$ \\
\hline Spread September & - & $\begin{array}{l}-6.390 \\
(-0.76)\end{array}$ \\
\hline Spread October & - & $\begin{array}{l}-8.950 \\
(-1.10)\end{array}$ \\
\hline Spread November & - & $\begin{array}{c}-16.960 \\
(-1.79)\end{array}$ \\
\hline Spread December & - & $\begin{array}{l}-8.480 \\
(-1.03)\end{array}$ \\
\hline
\end{tabular}

${ }^{1}$ All figures in percentages. The coefficiences of the Fama-French factors are not reported to save space. 
impact on the seasonal behaviour of the liquidity premium. An alternative might be to incorporate other potentially distorting aspects of equity trading around the turn of the year, such as taxes or institutional trading related to windowdressing.

\section{SUMMARY AND CONCLUSIONS}

Analysing the pricing of liquidity in equity markets should be one of the key topics in financial economics. Surprisingly, few studies have directly addressed this issue. From a theoretical point of view, there are only two models that explicitely relate, in a positive fashion, alternative measures of liquidity to expected returns. ${ }^{29}$ The issue is certainly difficult. B\&S (1994) assume a representative investor within a context where information asymmetry is the relevant motivation. This is clearly unsatisfactory. On the other hand, wellknown microstructure models are concerned with market dynamics and the endogeneous character of the order flow under asymmetric information. Unfortunately, these models do not connect their conclusions with equilibrium expected returns where aggregation becomes crucial. In fact, it is not even clear how to measure properly the cost of illiquidity.

From our point of view, all these elements have contributed to the relatively little attention received by the empirical relationship between expected returns and the cost of illiquidity. The small number of studies available are performed with measures of liquidity provided by market makers. Trading mechanisms driven by prices have been the focus of attention of this literature. It should also be recognized that bid-ask prices and, in general, data necessary for this type of research have become available quite recently.

Our paper reports the first empirical evidence of the relationship between bid-ask prices and stock returns in continuous auction markets, where liquidity is provided in the absence of market makers. Two alternative methods are employed. The two-step cross-sectional approach with different measures of beta and individual securities rather than portfolios, and a GLS pooled crosssection time series analysis.

In general, the results do not support the hypothesis that liquidity is positively priced in the Spanish market. Neither the bid-ask spread nor our measure of depth seem to be significantly associated with average returns.

Interestingly, our results tend to coincide with the previous evidence recently found in the US market. The liquidity premium seems to be negative for months other than January and, at the same time, there exists weak evidence of a positive, although non-significant, premium during January. We also find that, at the $10 \%$ level, there exists a significant difference between the premium for January and the premium for the rest of the year. In other words, there is some (rather weak) evidence suggesting that the premium for January seems to be significantly higher than the premium for months other than January.

${ }^{29}$ The papers of $A \& M$ and $B \& S(1994)$. 
The reasons behind these findings are certainly difficult to understand. It would be helpful to know whether similar empirical results occur in the Tokyo Stock Exchange or in the Paris Bourse. It may be that our basic model is not well specified and/or that the relative bid-ask spread by itself does not serve as a relevant measure of the cost of illiquidity. Also, as mentioned before, other institutional aspects might be considered before reaching further conclusions. Whatever the reason, all these results suggest that further research with more precise data and longer periods of time should certainly be encouraged. In particular, the short period of time considered by our study is a clear limitation of the paper. It is important to acknowledge the potential instability of the results. It may certainly be the case that longer data and a precise measure of illiquidity may change the results. Unfortunately, the reference point to which our limitations may be compared is quite unclear. In the previous tests for the US market with the exception of NASDAQ, bid and ask spreads for a given firm are measured by taking the average of the spreads of two days - beginning and end of the year. This procedure does not allow for the possibility of capturing the variability of the spread within the year. The adverse selection measure employed by B\&S is even more limited.

We are still waiting for the first comprehensive study of the relationship between market microstructure and asset pricing. Long periods of monthly data of either adverse selection or just effective bid-ask spreads instead of posted spreads are clearly necessary before reaching any conclusion regarding the pricing of liquidity. In the meantime, we have learned that market mechanisms with specialists like the NYSE, and market structures without market makers like the Spanish market tend to present similar and surprising results in terms of the seasonal behaviour of the compensation for bid-ask spreads.

\section{ACKNOWLEDGEMENTS}

We are grateful to Roberto Blanco from the Bank of Spain and Jorge Yzaguirre from the Spanish Stock Exchange for providing the data necessary to perform this study. This paper has benefited from the comments of seminar participants at the 1996 European Financial Management Association Meeting in Innsbruck, Universidad Carlos III in Madrid, Universidad de Valencia, Universidad del País Vasco, and two anonymous referees. We would also like to acknowledge the financial support provided by the Dirección General Interministerial Científica y Técnica (DGICYT), project no. PB94-1373. The contents of this paper are the sole responsibility of the authors.

\section{APPENDIX: IMPLEMENTING GMM WITH THE FAMA-FRENCH FACTORS}

In general, let $h_{l}(\theta)$ be the following $4 N \times 1$ vector: 


$$
h_{t}(\theta)=\left|\begin{array}{c}
\varepsilon_{1}\left(\alpha_{1}, \beta_{1 \mathrm{~m}}, \beta_{1 \mathrm{smb}}, \beta_{1 \mathrm{hml}}\right) \\
\varepsilon_{1}\left(\alpha_{1}, \beta_{1 \mathrm{~m}}, \beta_{1 \mathrm{smb}}, \beta_{1 \mathrm{hml}}\right) r_{\mathrm{m} t} \\
\varepsilon_{1}\left(\alpha_{1}, \beta_{1 \mathrm{~m}}, \beta_{1 \mathrm{smb}}, \beta_{1 \mathrm{hml}}\right) S M B_{t} \\
\varepsilon_{1}\left(\alpha_{1}, \beta_{1 \mathrm{~m}}, \beta_{1 \mathrm{smb}}, \beta_{1 \mathrm{hml}}\right) H M L_{t} \\
\cdot \\
\cdot \\
\varepsilon_{\mathrm{N}}\left(\alpha_{N}, \beta_{N \mathrm{~m}}, \beta_{N \mathrm{smb}}, \beta_{N \mathrm{hml}}\right) \\
\varepsilon_{\mathrm{N}}\left(\alpha_{N}, \beta_{N \mathrm{~m}}, \beta_{N \mathrm{smb}}, \beta_{N \mathrm{hml}}\right) r_{\mathrm{m} t} \\
\varepsilon_{\mathrm{N}}\left(\alpha_{N}, \beta_{N \mathrm{~m}}, \beta_{N \mathrm{smb}}, \beta_{N \mathrm{hml}}\right) S M B_{t} \\
\varepsilon_{\mathrm{N}}\left(\alpha_{N}, \beta_{N \mathrm{~m}}, \beta_{N \mathrm{smb}}, \beta_{N \mathrm{hml}}\right) H M L
\end{array}\right|
$$

and let $g_{T}(\theta)$ be

$$
g_{T}(\theta)=\frac{1}{T} \sum_{t=1}^{T} h_{t}(\theta)
$$

where $\theta$ is the $4 N \times 1$ vector $\left(\alpha_{1}, \beta_{1 \mathrm{~m}}, \beta_{1 \mathrm{smb}}, \beta_{1 \mathrm{hml}}, \ldots \ldots, \alpha_{N}, \beta_{N \mathrm{~m}}, \beta_{1 \mathrm{Imb}}, \beta_{1 \mathrm{hml}}\right)$.

From the model given by regression 5 , we are able to derive the moment conditions, $E\left[h_{t}(\theta)=0\right]$. The GMM selects an estimator, $\hat{\theta}$, so that the expression $\mathrm{Ag}_{T}(\hat{\theta})=0$ is satisfied. In other words, we equate to zero certain linear combinations of the moment conditions. The optimal weighing matrix can be shown to be given by $A^{*}=D_{0}^{\prime} S_{0}^{-1}$ where,

$$
D_{0}=E\left(\frac{\partial g_{T}(\theta)}{\partial \theta^{\prime}}\right)
$$

and

$$
S_{0}=\sum_{\tau=-\infty}^{+\infty} E\left\langle h_{t}(\theta) h_{t-\tau}(\theta)^{\prime}\right)
$$

The GMM estimator $\hat{\theta}$ has an asymptotic normal distribution with mean $\theta$ and asymptotic variance-covariance matrix $\left[D_{0}^{\prime} S_{0}^{-1} D_{0}\right]^{-1}$. Consistent estimators of $D_{0}$ and $S_{0}$ can easily be obtained. Thus, for the unrestricted case, the test statistic is shown to be constructed employing the well-known method for testing linear restrictions. ${ }^{30}$ Let $\phi_{1}$ be the unrestricted GMM test statistics. Under the null hypothesis we have:

$$
\phi_{1}=T \hat{\alpha}^{\prime}\left\{R\left(D_{T}^{\prime} S_{T}^{-1} D_{T}\right)^{-1} R^{\prime}\right\}^{-1} \hat{\alpha} \stackrel{\mathrm{a}}{\longrightarrow} \chi^{2}{ }_{N}
$$

where,

$R=I_{N} \otimes(1000)$

$R \hat{\theta}=\bar{\alpha}$

On the other hand, for the restricted case, we have,

${ }^{30}$ See MacKinley and Richardson (1991) for details. 


$$
g_{T}\left(\alpha=0, \beta_{\mathrm{m}}, \beta_{\mathrm{smb}}, \beta_{\mathrm{hml}}\right)=\frac{1}{T} \sum_{t=1}^{T} h_{t}\left(\alpha=0, \beta_{\mathrm{m}}, \beta_{\mathrm{smb}}, \beta_{\mathrm{hml}}\right)
$$

In this case, for each of the 16 portfolios we have four sample moments but only three parameters to be estimated. Hence, we have $4 N$ equations and $3 N$ unknown parameters and the system is overidentified. The test of these restrictions is given by:

$$
\phi_{2}=\operatorname{Tg}_{T}(\hat{\beta})^{\prime} S_{T}^{-1} g_{T}(\hat{\beta}) \stackrel{\mathrm{a}}{\longrightarrow} \chi^{2}{ }_{N}
$$

\section{REFERENCES}

Amihud, Y. and H. Mendelson (1986) Asset pricing and the bid-ask spread, Journal of Financial Economics, 17, 223-49.

Amihud, Y. and H. Mendelson (1989) The effects of beta, bid-ask spread, residual risk, and size on stock returns, Journal of Finance, 44, 479-86.

Basarrate, B. and G. Rubio (1990) A note on the seasonality in the risk-return relationship, Investigaciones Económicas, 14, 311-18.

Basarrate, B. and G. Rubio (1994) La Imposición Sobre Plusvalías y Minusvalías: Sus Efectos Sobre el Comportamiento Estacional del Mercado de Valores, Revista Española de Economía, 11, 247-77.

Biais, B., Hillion, P. and C. Spatt (1995) An empirical analysis of the limit order book and the order flow in the Paris Bourse, Journal of Finance, 50, 1655-89.

Brennan, M. and A. Subrahmanyam (1994) Market microstructure and asset pricing: on the compensation for adverse selection in stock returns. Finance Working Paper, Graduate School of Management, University of California, Los Angeles.

Brennan, M. and A. Subrahmanyam (1996) Market microstructure and asset pricing: on the compensation for illiquidity in stock returns, Journal of Financial Economics, 41, $441-64$.

Eleswarapu, V. (1996) Cost of transacting and expected returns in the Nasdaq market. Working Paper, University of Auckalnd, New Zealand.

Eleswarapu, V. and M. Reinganum (1993) The seasonal behavior of the liquidity premium in asset pricing, Journal of Financial Economics, 34, 373-86.

Fama, E. and J. MacBeth (1973) Risk, return and equilibrium: empirical tests, Journal of Political Economy, 81, 607-36.

Fama, E. and K. French (1992) The cross-section of expected stock returns, Journal of Finance, 47, 427-65.

Fama, E. and K. French (1993) Common risk factors in the returns on stocks and bonds, Journal of Financial Economics, 33, 3-56.

Foster, F. and S. Viswanathan (1993) Variations in trading volume, return volatility, and trading costs: evidence on recent price formation models, Journal of Finance, $\mathbf{4 8 ,}$ $187-211$.

Fowler, D. and C. Rorke (1983) Risk measurement when shares are subject to infrequent trading, Journal of Financial Economics, 12, 279-83.

Gibbons, M., Ross, S. and J. Shanken (1989) A test of the efficiency of a given portfolio, Econometrica, 57, 1121-52.

Glosten, L. (1994) Is the electronic open limit order book inevitable?, Journal of Finance, 49, $1127-61$.

Glosten, L. and L. Harris (1988) Estimating the components of the bid-ask spread, Journal of Financial Economics, 21, 123-42. 
Glosten, L. and P. Milgrom (1985) Bid, ask, and transaction prices in a specialist market with heterogeneously informed agents, Journal of Financial Economics, 14, 71-100.

Grinblatt, M. and S. Titman (1987) The relation between mean-variance efficiency and arbitrage pricing, Journal of Business, 60, 97-112.

Hamao, Y. and J. Hasbrouck (1995) Securities trading in the absence of dealers: trades and quotes on the Tokyo stock exchange, Review of Financial Studies, 8, 849-78.

Huang, R. and H. Stoll (196) Dealer versus auction markets: a paired comparison of execution costs on NASDAQ and the NYSE, Journal of Financial Economics, 41, 313-58.

Kothari, S., Shanken, J., and Sloan, R. (1995) Another look at the cross-section of expected returns, Journal of Finance, 50, 185-224.

Kyle, A. (1985) Continuous auctions and insider trading, Econometrica, 53, 1315-35.

Lee, C., Mucklow, B. and Ready, M. (1993) Spreads, depths, and the impact of earnings information: an intraday analysis, Review of Financial Studies, 6, 345-74.

Mackinley, C. (1995) Multifactor models do not explain deviations from the CAPM, 38, $3-28$.

MacKinley, C. and M. Richardson (1991) Using generalized method of moments to test mean-variance efficiency, Journal of Finance, 46, 511-27.

Petersen, M. and D. Fialkowski (1994) Posted versus effective spreads: good prices or bad quotes? Journal of Financial Economics, 35, 269-92.

Rubio, G. (1988) Further international evidence on asset pricing: the case of the Spanish capital market, Journal of Banking and Finance, 12, 221-42.

Rubio, G. (1995) Further evidence on performance evaluation: portfolio holdings, recommendations, and turnover costs, Review of Quantitative Finance and Accounting, 5, 127-53.

Rubio, G. and M. Tapia (1996) Adverse selection, volume, and transactions around dividend announcements in a continuous auction system. Forthcoming in European Financial Management, 2, 39-67.

Sentana, E. (1995a) Riesgo y rentabilidad en el mercado de valores Español, Moneda y Crédito, 200, 133-60.

Sentana, E. (1995b) Risk and return in the Spanish stock market: II. Working Paper, CEMFI, Madrid.

Shanken, J. and M. Weinstein (1991) Macroeconomic variables and asset pricing: further results. Working Paper, Managerial Economics Research Studies, Bradley Policy Research Center, University of Rochester. 